\title{
Design and Evaluation of a Multimodal Science Simulation
}

\author{
Brianna J. Tomlinson ${ }^{1}$, Prakriti Kaini ${ }^{1}$, Siyan Zhou ${ }^{1}$, Taliesin L. Smith ${ }^{2}$, Emily B. Moore ${ }^{2}$, \\ and Bruce N. Walker ${ }^{1}$ \\ ${ }^{1}$ Georgia Institute of Technology \\ Atlanta, USA \\ \{btomlin, prakriti.kaini, szhou324\}@gatech.edu, \\ bruce.walker@psych.gatech.edu \\ ${ }^{2}$ University of Colorado Boulder \\ Boulder, USA \\ \{taliesin.smith, emily.moore\}@colorado.edu
}

\begin{abstract}
We present a multimodal science simulation, including visual and auditory (descriptions, sound effects, and sonifications) display. The design of each modality is described, as well as evaluation with learners with and without visual impairments. We conclude with challenges and opportunities at the intersection of multiple modalities.
\end{abstract}

\section{Author Keywords}

Multimodal; evaluation; interactive simulation; learning; visual impairment.

\section{INTRODUCTION}

The use of multiple modalities within a single interactive learning experience can support diverse learners [9]. In this demonstration we use visual display and auditory display verbal description, sound effects, and sonifications - within an interactive simulation (sim) to support exploration of the physics concept static electricity for learners with and without visual impairments.

Our aim was to create a single sim with multiple modality 'layers' capable of being accessed at once or in different combinations to meet the needs of individual users in the moment. We built upon prior work on interactive sims [7,13], description of interactives [6,14], and auditory display of learning tools $[18,19,20]$, and evaluated the sim from the perspective of providing universal access [2].

\section{MULTIMODAL DESIGN OF JOHN TRAVOLTAGE SIM}

The PhET physics sim John Travoltage $[10,11]$ consists of a man, John, standing on a rug with his hand reaching out towards a door. Rubbing his foot on the rug results in the transfer of negative charges from the rug onto John's body. John's arm can be moved in a 360-degree circle, resulting in his hand being closer or farther from the doorknob. Depending on the amount of negative charges on John's body and the distance of his hand from the doorknob, the

Permission to make digital or hard copies of part or all of this work for personal or classroom use is granted without fee provided that copies are not made or distributed for profit or commercial advantage and that copies bear this notice and the full citation on the first page. Copyrights for third-party components of this work must be honored. For all other uses, contact the Owner/Author.

ASSETS '18, October 22-24, 2018, Galway, Ireland

(C) 2018 Copyright is held by the owner/author(s).

ACM ISBN 978-1-4503-5650-3/18/10.

https://doi.org/10.1145/3234695.3241009 electrons can discharge - transferring to the doorknob and 'shocking' John. Science learners from upper elementary school through college can explore the relationship between the amount of charge on John's body and the distance of his hand from the doorknob that results in discharge/shock. Learners can navigate the sim using a mouse, touchscreen, touchpad, keyboard, or other input devices, and access descriptions with screen reader software.

\section{Visual Display}

John is a black-and-white semi-realistic character striking a playful pose (arm and leg appearing poised for action) in a room. John, the small rug he's standing on, and the door are central. A small window looking out onto a tree are off to the left. Negative charges are shown as small blue balls.

\section{Auditory Display}

\section{Sound Effects \& Sonifications}

Multiple types of sound effects and sonifications [19] listed in Table 1, were designed [11], to support visual and nonvisual sim experiences. Sound is played using Web Audio [1] and PhET's sound library Tambo [12].

\begin{tabular}{c|l}
$\begin{array}{c}\text { Sim } \\
\text { Feature }\end{array}$ & \multicolumn{1}{|c}{ Mapping } \\
\hline $\begin{array}{c}\text { Foot } \\
\text { Rubbing }\end{array}$ & Carpet rubbing sound (Auditory Icon) \\
Charge & Number, pitch increases/decreases as number \\
Transfer & increases/decreases (Sonified Earcon) \\
Charges & Static-like, increasing number increases \\
on Body & volume and playback rate (Sonification) \\
Arm & Ratchet, pitch increases as hand-doorknob \\
Rotation & distance decreases (Sonified Auditory Icon) \\
Discharge & Electrical Zap (Auditory Icon) \\
Shock & "Gazouch" (Speech)
\end{tabular}

Table 1. Sound mappings in John Travoltage sim.

\section{Description}

Description can be accessed using screen reader software to support non-visual learning experiences. Dynamic description provides an always-available description of the current state of the sim. As learners interact with John's arm or leg, they are provided with position values and realtime alerts. Descriptions highlight the key relationships: amount of charge and hand's distance from doorknob. With John's leg, position values indicate when "Foot rubbing on 
rug" and when "Foot off rug," and alerts indicate charge transfer, e.g., "Electrons on body: 3." For the arm, position values indicate distance from doorknob, and regions and landmark positions, as well as changes in direction and progress toward or away from doorknob. Description is structured using PhET's description framework [14], designed [5,8] and implemented using a Parallel DOM [15].

\section{EVALUATION OF MULTIMODAL DESIGN}

As part of an iterative design process, we utilized rounds of think-aloud interviews $[3,8,17]$ with learners with disabilities (visual impairments or intellectual and developmental disabilities (I/DD)) and without disabilities from primary school age to adult, to inform design of all sim features. We also included feedback from teachers, content experts, and expert screen reader users. To evaluate later design stages, we conducted semi-structured interviews of adult learners with visual impairments $(n=5)$ and think-aloud interviews with children $(n=3)$ and college students $(n=3)$ without visual impairments.

\section{Semi-structured Interviews}

Interviews began with 10 minutes of free exploration of the sim. Then, participants answered a series of open-ended questions about their experiences and interpretation of: sim navigation, description, and sound. Last, participants completed three surveys: A subset of questions from the BUZZ [16] audio user experience scale, eliciting feedback on the sound aesthetics; a 4-question usability scale, UMUX, eliciting feedback on the overall sim experience [4]; and a demographics and technology use survey.

\section{RESULTS}

\section{Experience: Description + Sound Effects/Sonifications}

Five adult screen reader users with visual impairments, selfdescribed: low-vision (2) or blind (3), used the sim with no visual display available. Participants rated the aesthetics of the sim as a $25.8(\mathrm{SD}=2.3)$ out of 28 . They also rated the overall usability of the sim as $20.2(\mathrm{SD}=4.3)$ out of 24 . Four of the participants specifically mentioned liking how the sounds and descriptions worked together to help them know what was happening. From open-ended questions, all reported the sounds and descriptions as being useful, and most (4/5) commented positively on description clarity.

Experience: Visual Display + Sound Effects/Sonification Three children (7-9 years old) and three college students (all with no visual impairment) explored the sim without descriptions in think-aloud interviews. All learners explored the sim fully and described relationships between amount of charge and arm/hand location. Some sounds seemed to be attended to less by the children (e.g., charges on body), though no negative impact was observed in these cases. All students made relevant interpretations of the sound mappings, though not necessarily the intended mapping. For example, one student (9-year old) described the arm rotation/ratchet mapping as sounding "like a xylophone," while another (college student) described the same sound as "like a wind-up toy." Both learners indicated the sound was present to provide feedback on arm location changes.

\section{DISCUSSION}

All eleven participants used the same sim, though they accessed different combinations of modalities during exploration. All were able to effectively use the sim and explored the key relationships in the sim. Some difficulties related to the relative volume of different sounds in the auditory display were found. When sound effects/sonifications were perceivable to learners, they indicated understanding of the sound/feature mappings. All learners indicated that, in general, they enjoyed the sim, and many indicated the auditory modality was helpful.

We encountered many challenging design decisions while creating the multimodal sim. Some challenges were specific to each modality (e.g., refining interaction, visuals, and descriptions to each scaffold learners to explore the key concepts; refining description to be concise and understandable across age groups; ensuring sound effects/sonifications were cohesive). Many challenges arose from the intersection of two or more modalities (e.g., designing sound effects/sonifications to layer with and complement both visuals and description - simultaneously).

Ensuring a coherent experience across all modality layers and their combinations required coordinated efforts across an interdisciplinary team and evaluation with diverse learners, overall a difficult but rewarding design process.

\section{CONCLUSIONS}

We present a multimodal science simulation, with visual display and robust auditory display (description, sound effects, and sonifications) capable of supporting learners with and without visual impairments. Building on our prior work in developing navigation and description for complex interactives, we introduced the design and evaluation of a simulation with new auditory display components, and its evaluation with learners utilizing different combinations of modalities (sound effects/sonifications with visual display or description). This work contributes to continued advancement of approaches and techniques to developing and evaluating accessible interactives for learning.

\section{ACKNOWLEDGMENTS}

We thank John Blanco (PhET Interactive Simulations), Mike Winters (Georgia Tech), Ashton Morris (Parallax Productions), and Jonathan Hung (Inclusive Design Research Center), for their significant contributions to the design and development of John Travoltage. This material is based on work supported by the National Science Foundation under DRL-1503439 and DRL-1621363.

\section{REFERENCES}

1. Paul Adenot, Chris Wilson. Web Audio API. W3C Working Draft 08 December 2015. Retrieved June 16, 2018 from http://www.w3.org/TR/webaudio/

2. Dana Ayotte, Joanna Vass, Jess Mitchell, and Jutta Treviranus. (2014, June). Personalizing interfaces 
using an inclusive design approach. In International Conference on Universal Access in Human-Computer Interaction (pp. 191-202). Springer, Cham.

3. Sambhavi Chandrashekar, Tony Stockman, Deborah Fels, and Rachel Benedyk. 2006. Using think aloud protocol with blind users: a case for inclusive usability evaluation methods. In Proceedings of the 8th international ACM SIGACCESS Conference on Computers and Accessibility (ASSETS '06). ACM, New York, NY, USA, 251-252. DOI=http://dx.doi.org/10.1145/1168987.1169040

4. Kraig Finstad. 2010. The usability metric for user experience. Interact Comput 22, 5: 323-327.

5. Jonathon Hung. PhET John Travoltage simulation design (2016). Retrieved April 12, 2018 from https://wiki.fluidproject.org/display/fluid/PhET+John+ Travoltage + Simulation + Design

6. Kyle Keane and Christine Laverentz. 2014. Interactive scientific graphics: Recommended practices for verbal description. Technical Report. Wolfram Research, Inc., Champaign, IL

7. Emily B. Moore, Timothy A. Herzog, Katherine K. Perkins. 2013. Interactive simulations as implicit support for guided-inquiry. Chem Educ Res Prac 14, 3: 257-268.

8. Emily B. Moore, Taliesin L. Smith, Jesse Greenberg. 2018. Keyboard and screen reader accessibility in complex interactive science simulations: Design challenges and elegant solutions. In International Conference on Universal Access in Human-Computer Interaction, pp. 385-400. Springer, Cham.

9. Zeljko Obrenovic, Julio Abascal, and Dusan Starcevic. 2007. Universal accessibility as a multimodal design issue. Commun. ACM 50, 5 (May 2007), 83-88. DOI=http://dx.doi.org/10.1145/1230819.1241668

10. PhET Interactive Simulations. John Travoltage. Retrieved June 12, 2018 from https://phet.colorado.edu/en/simulation/travoltage

11. PhET Interactive Simulations. Prototype: Multimodal John Travoltage, Retrieved June 12, 2018 from https://bayes.colorado.edu/dev/html/phet-io-wrappersonification/1.0.0-dev.56/phet-io-wrappersonification/john-travoltage/html/john-travoltagesonification.html? sonificationFile=sonificationMix\&ac cessibility
12. PhET Interactive Simulations. Tambo. Accessed November 20, 2017 from https://github.com/phetsims/tambo

13. Noah S. Podolefsky, Emily B. Moore, Katherine K. Perkins. 2013. Implicit scaffolding in interactive simulations: Design strategies to support multiple educational goals. arXiv:1306.6544. Retrieved from https://arxiv.org/abs/1306.6544

14. Taliesin L. Smith. 2016. Access, action, \& agency: Inclusive design for the non-visual use of a highly interactive science simulation. Masters Research Project. OCAD University, Toronto, Canada.

15. Taliesin L. Smith, Jesse Greenberg, Sam Reid, and Emily B. Moore. 2018. Parallel DOM Architecture for Accessible Interactive Simulations. In Proceedings of the Internet of Accessible Things (W4A '18). ACM, New York, NY, USA, Article 4, 8 pages. DOI: https://doi.org/10.1145/3192714.3192817

16. Brianna J. Tomlinson, Brittany E. Noah, and Bruce N. Walker. 2018. BUZZ: An Auditory Interface User Experience Scale. In Extended Abstracts of the 2018 CHI Conference on Human Factors in Computing Systems (CHI EA '18). ACM, New York, NY, USA, Paper LBW096, 6 pages. DOI: https://doi.org/10.1145/3170427.3188659.

17. Brianna Tomlinson, Jared Batterman, Prakriti Kaini, Bruce N. Walker, and Emily B. Moore. (2018) Supporting Simulation Use for Students with Intellectual and Developmental Disabilities. J Technol Pers Disabil, 202-218.

18. Brianna J. Tomlinson, Jared Batterman, Yee Chieh Chew, Ashley Henry, and Bruce N. Walker. 2016. Exploring Auditory Graphing Software in the Classroom: The Effect of Auditory Graphs on the Classroom Environment. ACM Trans. Access. Comput. 9, 1, Article 3 (November 2016), 27 pages. DOI: https://doi.org/10.1145/2994606

19. Bruce N. Walker and Michael A. Nees. 2011. Theory of sonification. In The Sonification Handbook, Thomas Hermann, Andy Hunt and John G Neuhoff (eds.). Logos Verlag, Berlin, 9-39.

20. R. Michael Winters, Brianna Tomlinson, Bruce Walker, and Emily B. Moore. In press. Sonic Information Design for Physics Education. Ergon. Des. 